15 that of careful observance and patient analysis. liy kcepms the details well in our memory--instead of trying to forget them-we in time find out their position in our noso-taxic scheme, either in the ligrht of our own later experience or of that of others.

These remarks are certainly true of the specialtics to which thr, Journal is devoted, and are well exemplified by the descriptions of certain morbid conditions of the nose which up till comparatively. recent times have not been clearly distinguished. Thus, certain cases registered as purulent rhinitis or ozxna, but of "atypical" forms, arc now recognized at once as cxamples of disease of the nasal sinuses. Again, most of us have been sorcly puzzled at times by the occasiona! occurrence of comparatively markccl ulccration of the tonsils, the nature of which we have been apt to consider as syplilitic, bu "atypical" in many respects, and especially in regard to the extreme rapidity with which they heal. It has fallen to the lot of 1$) \mathrm{r}$. Vioure, of Bordeaus, to see a number of such cases and to satisfy himself of their non-specific nature. He recently read a paper on the subject before the Societí Français de Laryngologie, etc., which we have the privilege of placing before our readers in this Journal.

Of similar interest are the "thirty-seren cascs of serous discase of the maxillary sinus" detailed by 1)r. Noltenius, of Bremen ("Nonatsschrift für Ohrenheilkunde," April, 1895 ), in which the symptoms wcre usually those of hypertrophic rhinitis, but "atypical," inasmuch as the cause of the subjective obstruction was not obvious on inspection, nor until exploratory aspiration of the antrum was carricd out. This was accomplished by means of a necdle and uyringe through the inferior meatus, a variable amount of scrous, fluid being withdrawn. Simple puncture and removal of the fluid by means of a modification of Kratses trocar, also introduced through the outer wall of the inferior meatus, was in all cases sufficient to effect a cure without any irrigation or further treatment whatever. Many of us must be able to look back to cases presenting similar "atypical" characteristic:, which at study of this communication may help to clcar up.

)undas (irant.

\title{
ABSTRACT of a LECTURE upon the relation between the MOYEMENTS of the EYES and the MOYEMENTS of the HEAD.
}

\author{
By A. CRUM BROWx, M.D., F.R.S.
}

HaVING experimentally demonstrated that our sensation of "the fixity of the earth" is associated with certain intermittent unconsciously executcl compensatory movements of the eycballs, the author proceded to consider the probable cause or mechanisin through threc sources of information, viz.:-(I) from personal experiments, (2) anatomical observations and measurements, and (3) from observations of the effects of injuric: to the labyrinth. 
He demonstrated the first group by means of a smoothly revolving table made for lighthouse purposes, which, from its accurate adjustment, could be driven at uniform speeds, thereby excluding any sensations due to inertia of the soft parts of the body. The patient being seated in an upright position, with eyelids closed, the author observed that, on rotating the table at a moderate speed, the eyeballs executed regular jerky movements, and were attended by sensations of rotation; but both movements and sensations ceased after a few revolutions, only to return on stopping or slowing the table, or altering the axis of rotation of the head. These phenomena he further illustrated with the well-known trick of walking several times round a poker held vertically, the forehead resting on the knob, and then attempting to walk erect.

This information he interpreted as substantial evidence of the localization of a special mechanism in the head. Of the view that the semicircular canals (as originally advanced by Flourens) were the responsible organ he sought confirmation in a consideration of their physical arrangement, and their relation to the several planes he investigated by a specially constructed goniometer. He concluded that the stretching of the membranous ampulla was the real cause of the sensation of rotation, through excitation of the cristæ acusticæ, for when either canal was rotated in a direction following the ampulla, the pressure in the endolymph of the ampulla was increased, but in the peri-lymph was decreased. Cessation or a reversal of the rotation caused reverse pressures and corresponding changes in sensations, for relaxation of ampullary walls and diminution of endo-lymph pressure did not stimulate the crista. This hydro-kinetic theory was first advanced by Mach of Prague and Breuer of Vienna. Although Cyon, by plugging, caused an increase of pressure in the bony canals, without any nystagmus or rotatory movements of the head, this did not negative, but supported the author's views that an increase of intra-membranous pressure was essential to the creation of the foregoing phenomena.

The author did not agree with the view that the semicircular canals were concerned in appreciating the direction of sound.

He further aptly compared the ampullary organs with clerks in a merchant's office, of whose usefulness we were only aware when they ceased to work properly.

The intimate correlation between the ocular movements and the ampullary organs was strongly supported by the fact that a large proportion of deaf-mutes were strangers to the sensation of rotation, and exhibited no jerking movements of the eyeball when rotated; the want of these organs being supplied by a greater activity and increased acuteness of other sense organs-it being a matter of pathological observation that, in the subjects of deaf-mutism, the semicircular canals were frequently absent.

(Wyatt Wingrave) Dundas Grant. 